\title{
Extract from Broccoli by-products to extend the Shelf Life of Fish Burgers
}

\author{
Luisa Angiolillo ${ }^{1}$, Sara Spinelli ${ }^{1}$, Valeria Marinelli ${ }^{1}$, Amalia $_{\text {Conte }}{ }^{1} \&$ Matteo Alessandro Del Nobile $^{1}$ \\ ${ }^{1}$ Department of Agricultural Sciences, Food and Environment, University of Foggia, Via Napoli, 25 - 71121 \\ Foggia, Italy \\ Correspondence: Amalia Conte, Department of Agricultural Sciences, Food and Environment, University of \\ Foggia, Via Napoli, 25 - 71121 Foggia, Italy. Tel: 39-088-158-9240, E-mail: amalia.conte@unifg.it
}

Received: July 3, 2018 Accepted: August 2, $2019 \quad$ Online Published: February 26, 2019

doi:10.5539/jfr.v8n2p56 URL: https://doi.org/10.5539/jfr.v8n2p56

\begin{abstract}
The present work was aimed to compare the extraction efficiency of two techniques, the supercritical fluid extraction (SFE) and the ultrasound assisted extraction (UAE) applied to broccoli by-products and utilize the most active extract for prolonging the shelf life of fish burgers. To the aim, the antimicrobial activity of two different percentages of extracts (2\% and 5\%) were tested against Pseudomonas spp. and Candida krusei. Once the SFE was chosen as the best extraction method, the extract was added to sea-bram burgers to prolong the shelf life. To the aim, both microbiological quality and sensory properties were monitored during refrigerated storage. The SFE-extract addition to fish burgers determined a shelf life increase by about 7 days respect to control samples, without any negative sensory perception.
\end{abstract}

Keywords: antimicrobial activity broccoli extracts, by-products, fish burger, shelf life

\section{Introduction}

The use of vegetal products as source of bioactive and healthful components is a concept which drew consumer attention because of the increasing demand for high nutritional foods, free of synthetic preservatives. In addition to the increasing attention towards nutritional aspects, food industry has to find innovative solutions to ensure an extended food shelf life, in line with the global commerce which promotes the transportation of foods worldwide and in line with the modern consumer lifestyle, more oriented towards limited time available for food supply. In order to ensure an adequate shelf life, the transport of highly perishable fish products, needs a deep control of microbial quality (Widsten, 2014) and for this reason, chemical preservatives could be an ideal choice to achieve a good quality (Botterweck et al., 2000). Despite their utility, chemical preservatives may pose adverse risks to human health causing for example carcinogenesis. As a consequence, researchers are trying to find natural products without side effects. The rise of microbial food outbreaks determined by consumption of ready to eat foods, represent another problem to be solved. Unfortunately, current technologies are inefficient to completely control microbial spoilage. In particular, fish products are an ideal environment for microbial growth because of their nutritional profile and their high content of water (Gill et al., 2002). Considering consumer demand for minimally processed foods, alternative solutions for shelf life prolongation, need to be found. Vegetal by-products such as leaves, flowers, seeds and peels have some natural antimicrobial compounds (Baydar et al., 2004) capable of being used both to improve microbial quality and to promote sustainable practices in order to reuse wastes (Martin et al., 2012). Brassica oleracea belongs to the Brassicaceae family which comprises 3500 species such as cauliflower, broccoli, kale, cabbage and Brussels sprouts. These vegetable products are a consistent part of human diet worldwide because they have been reported to have anticancer antioxidant and antimicrobial properties due to their phenols content (Keck \& Finley, 2004). The bioactive vegetable phenols consists in flavonoids, phenolic acids and tannins, mostly non volatile capable of being extracted by means of aqueous and organic solvents (Wijngaard et al., 2009). The most common method for the separation of these compounds, consists in a liquid solvent technique. This process presents some limitation such as: high energy cost, elevated solvent use, high temperatures, low selectivity (Pormortazavi \& Hajimirsadegui, 2007). To solve these limitations, could be useful the adoption of other kind of extraction techniques. Supercritical fluid extraction (SFE) and Ultrasound-assisted (UAE) leaching are modern extraction techniques, still little applied but more efficient In the case of SFE extraction, solvents can be used above their critical point, determining in 
this way, diffusivity values more than two times higher respect to those of other liquids. The advantages of this technique are: improved selectivity, automation, environmental safety (Brunner 2005). The use of $\mathrm{CO}_{2}$ as solvent, allows to avoid chemical and toxic solvents. The fact that $\mathrm{CO}_{2}$ is volatile, improves chemical and thermal stability of bioactive substances. The disadvantage consists in its no polar nature that limits its use with polar compounds and for this reason polar co-solvents can be used to increase the extraction ability (Silva et al., 2008). The UAE is based on sound mechanical waves that go beyond human hearing, whose frequencies are superior to $20 \mathrm{kHz}$. This type of extraction requires a liquid medium previously selected that allows ultrasonic wave to propagate up to the product, also preserving the integrity of the molecules that can be thermolabile, thermostable, hydrosoluble, and liposoluble. This is possible due to the cavitation forces resulting from the ultrasound application. The ultrasound waves determine the formation of cavitation forces which enabled the collapse of bubbles into the medium. The resulted mechanical effects such as: particle collisions, solvent penetration and cell destruction, improve the mass transport rates of bioactive compounds, outside the food matrix (Gonzales et al., 2014). Finally, this extraction method, can be considered natural since, its use of water as solvent and efficient, in consequence of high extraction yield. In literature studies about the use of vegetal by-products are focused on the extraction optimization conditions to obtain potential bioactive compounds, but the applications of the extracted substances to foods are very scarce and completely absent in the case of broccoli by-products extracts. Despite the recognized antimicrobial activity of broccoli extracts (Jaiswal et al., 2011; Correa et al., 2014; Sibi et al.,, 2013) no studies are available on stems and leaves from broccoli by means of sustainable extraction techniques such as SFE and UAE. Therefore, this work aims to compare the extraction efficiency of SFE and UAE on the antimicrobial activity maintenance of broccoli by-products. Then, the extract from SFE has been added to sea-bream burgers with the aim of prolong its shelf life. To prove its effectiveness, microbial and sensory descriptors have been analyzed.

\section{Material and methods}

\subsection{Raw Materials}

Broccoli stems and leaves (Brassica oleracea) were purchased from a local company near to Foggia (Southern Italy). Once arrived at the laboratory, samples were dried at $30-35^{\circ} \mathrm{C}$ for 48 hours using a dryer (SG 600, Namad, Rome, Italy). Then, all dried stems were reduced to powder by means of a mill (16/BV Beccaria s.r.l., Cuneo, Italy) and kept at $4{ }^{\circ} \mathrm{C}$ untilization.

Sea-bram (Sparus aurata) was provided by a fisherman of Mnfredonia (Foggia, Italy) and after being cleaned and eviscerated, it was cut into steaks of $400 \mathrm{~g}$ and transported under ice to the laboratory. After having been thawed at $4{ }^{\circ} \mathrm{C}$, all fillets were used for burger preparation.

\subsection{Extraction Techniques}

Broccoli extract (GME) was obtained by means of ultrasound assisted extraction UAE (USR-1500-50WL, Weal s.r.l., Milan, Italy) using only water as solvent. In the reactor dried stems were suspended in water at a ratio of $1: 10(\mathrm{w} / \mathrm{v})(2.5 \mathrm{Kg} / 25 \mathrm{~L})$ and ultrasonically treated for 60 minutes at acoustic frequency of $25 \mathrm{kHz}$ and with ultrasonic power density of $50 \mathrm{~W} / \mathrm{L}$. The obtained extract was homogenized and a part of this was dried under vacuum at $30^{\circ} \mathrm{C}$ in an oven. The residue was recovered centrifuging at $6000 \mathrm{rpm}$ for 10 minutes, using water ( 25 $\mathrm{mL})$ to re-suspend the extract.

For the supercritic fluid estraction SFE, experiments were made as described by Arnáiz et al. (2016), using the Speed SFE-2 (Applied Separation, Allentown, USA)supercritical fluid extractor. The instrument consists of two pumps, one to deliver the solvent and the other used for the addition of an organic co-solvent (ethanol). The operative conditions were: temperature at $35^{\circ} \mathrm{C}$, pressure at 50 bar and $\mathrm{CO}_{2}$ flow rate of $2 \mathrm{~L} / \mathrm{min}$. The process, as described by the overall extraction curve (OEC) lasted 140 minutes and consisted of 7 cycles. Briefly, $33 \mathrm{~g}$ of broccoli dried powder were placed into the extraction vessel and after the reach of the set temperature, the pressurization started. The extract was collected in a separate vessel while, $\mathrm{CO}_{2}$ was depressurized using a heated valve. Finally, the extract was vacuum dried at $30{ }^{\circ} \mathrm{C}$ in order to remove ethanol and re-dissolved in $25 \mathrm{~mL}$ of absolute ethanol, in order to be centrifuged at $6000 \mathrm{rpm}$ for 10 minutes (5804 R, Eppendorf, Milan, Italy) before chemical analyses.

\subsection{In vitro Tests for the Antibacterial Activity}

Broth dilution method was adopted and two strains of Pseudomonas spp. (isolated from spoiled fresh cheese) and a strain of Candida krusei (isolated from spoiled cream cheese) were used as test microorganisms. The

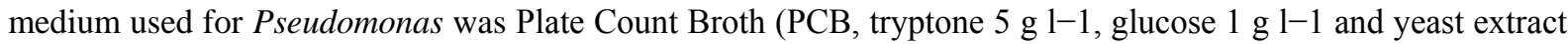
$2.5 \mathrm{gl}-1$, Oxoid) while for Candida krusei, the media was Sabouraud Dextrose Broth (Mycological Peptone 
$10.00 \mathrm{~g} / \mathrm{L}$ and Dextrose $20.00 \mathrm{~g} / \mathrm{L}$ ). the stock cultures were allowed to grow overnight at $25^{\circ} \mathrm{C}$ and immediately after, the two strains were mixed at $1 \%$ each in order to obtain a cocktail solution of about $10^{4} \mathrm{CFU} / \mathrm{ml}$. Growth experiments were made using the Japanese Industrial Standard (JIS) Z 2801:2000 (Anonymous, 2000). PCB and $\mathrm{SAB}$ cultures were inoculated into three different tubs consisting of: Broccoli extract (EXT), and ethanol (ETH) or water (W) as control experimental samples. All the afore-mentioned samples were tested at two different percentages: $5 \%(\mathrm{v} / \mathrm{v})$ and $2 \%(\mathrm{v} / \mathrm{v})$. For each experimental sample (EXT, ETH, W) seven tubes were prepared in order to follow the microbial growth for one week. A proper amount of target microorganism was inoculated in each tube and incubated at $25^{\circ} \mathrm{C}$ for $24 \mathrm{~h}$. Samples were diluted using a sterile saline solution $(10 \mathrm{~mL})$ stirred for $180 \mathrm{~s}$, then plated on Pseudomonas Agar Base (PAB, Oxoid) and Sabouraud Dextrose Agar (SAB, Oxoid) and incubated at $25^{\circ} \mathrm{C}$ for $48 \mathrm{~h}$. Pseudomonas enumeration, the medium was modified with Pseudomonas CFC selective supplement while Sabouraud Dextrose Agar, with $0.1 \mathrm{~g} / \mathrm{L}$ of chloramphenicol (C. Erba, Milan, Italy). All analyses were performed twice. With the aim of comparing the effectiveness of broccoli extracts against the target microbial groups, data were showed as $\log$ reduction $(\Delta)$, that is:

$$
\Delta=\log \mathrm{CFU}_{\mathrm{W}} \mathrm{g}^{-1}-\log \mathrm{CFU}_{\mathrm{EXT}} \mathrm{g}^{-1}
$$

where $\log$ CFUw is the cell load of control sample that is water and $\log \mathrm{CFU}_{\mathrm{EXT}}$ is the cell load of broccoli extracts. To better understand the differences between the two extraction methods in antimicrobial activity preservation, another index was calculated, (antimicrobial efficiency, AE) dividing $\Delta$ to the dry weight of the extract $\left(\mathrm{EXT}_{\mathrm{DW}}\right)$ as follows:

$\mathrm{AE}=\Delta / \mathrm{EXT}_{\mathrm{DW}}$

\subsection{Fish Burger Preparation}

For fish burger preparation, $832 \mathrm{~g}$ of minced fish meat obtained by using a domestic food processor (Multichef, Ariete, Firenze, Italy) was flavoured with, $41.6 \mathrm{~g}$ of whey protein foam soaked with $104 \mathrm{~g}$ of olive oil (Farmalabor, Canosa di Puglia, Italy), according to the work of Conte et al. (2011), 52g of potato flour (Bongiovanni, Villanova Mondovì (CN), Italy), $5.2 \mathrm{~g}$ of salt and $5.2 \mathrm{~g}$ of oregano (CNT sample). The second control sample consisted in sea-bram burger with $5 \%(\mathrm{w} / \mathrm{w})$ of ethanol (ETH). The active formulation (EXT) had the same composition of control samples with $5 \%(\mathrm{w} / \mathrm{w})$ of broccoli extract obtained by means of supercritic fluid extraction (SFE). The fish patties were homogenized in a bowl mixer for $5 \mathrm{~min}$ and divided into three batches (1040 $\mathrm{g}$ each) made of 26 burgers of $40 \mathrm{~g}$ each. Each burger was shaped by means of a metal shaper in order to obtain $1 \mathrm{~cm}$ thickens and $10 \mathrm{~cm}$ diameter. All burgers were packaged in an anti-fog high-barrier multilayer film made of polyethylene terephthalate, ethylene-vinyl alcohol and polyethylene, with oxygen transmission rate (OTR) of $6.19 \mathrm{cc} / \mathrm{m}^{2}$ day, and water vapor transmission rate (WVTR) of $1.208 \mathrm{~g} / \mathrm{m}^{2}$ day, thickness of $50 \mu \mathrm{m}$ (Di Mauro Officine Grafiche spa, Salerno, Italy). The storage temperature was $4{ }^{\circ} \mathrm{C}$.

\subsection{Microbiological Analyses}

Twenty grams of sea-bream burgers were diluted with $180 \mathrm{~mL}$ of $\mathrm{NaCl}$ solution $0.9 \%$ using a Stomacher LAB Blender 400 (Pbi International, Milan, Italy). The same diluent was used for decimal dilutions which were plated on appropriate media in Petri dishes. Nordic Committee on Food Analyses (2006) and the International Commission on Microbiological Specifications for Foods, ICMSF, (1986) prescribe for fresh water and marine species, the following microbiological limit: $5 \times 10^{6} \mathrm{CFU} / \mathrm{g}$ for aerobic plate count (APC) at $30^{\circ} \mathrm{C}, 2 \cdot 10^{2} \mathrm{CFU} / \mathrm{g}$ for coliforms (Altieri et al., 2005), $10^{8} \mathrm{CFU} / \mathrm{g}$ for Pseudomonas spp and $10^{6} \mathrm{CFU} / \mathrm{g}-10^{7} \mathrm{CFU} / \mathrm{g}$ for hydrogen sulphide-producing bacteria and psychrotolerant-heat-labile aerobic bacteria, respectively (Koutsoumanis and Nychas 2000; Dalgard 1995), and The media used for the study were supplied by Oxoid (Milan, Italy). Analyses were conducted in duplicate on two different samples. The acceptability limit was determined using the modified version of the Gompertz, equation fitted to the experimental data, (Conte et al., 2009; Del Nobile et al., 2009).

\subsection{Sensory Analysis}

A time intensity descriptive sensory evaluation was made following the Codex Alimentarious Commission guidelines (WHO, 1999) by 10 trained panelists from the Department of Agricultural Sciences, Food and Environment of the University of Foggia (Angiolillo et al., 2017). Panelists were asked to express their judgement on burgers color, odor, juiciness, texture, taste and whole quality before and after cooking. All burgers were coded by a letter and presented individually to each panelist in random order. The e xperimental burgers were cooked in a microwave oven to an internal temperature of about $57^{\circ} \mathrm{C}$. The panelists used a 9-point scale where the score 1, corresponded to extremely dislike while the score 9 to like extremely (Patsias et al., 2006; Boskou \& Debevere, 2000). The threshold value was set to 5 The sensory acceptability limit (SAL) was 
calculated fitting all data with the modified version of the Gompertz equation (Conte et al., 2009; Del Nobile et al., 2009). The quantitative analysis was performed during three replicates sessions on different days at the same hour of each day.2.7 Statistical analysis

All the results were using one-way Anova analysis. In the specific a Duncan's multiple range test, with the option of homogeneous groups $(\mathrm{P}<0.05)$, was used to determine significance among differences. The software used for the scope was Statistica 7.1 for Windows 152 (StatSoft Inc.,Tulsa, OK, USA) was used.

\section{Results and Discussion}

\subsection{In vitro Antimicrobial Activity of Broccoli by-products}

To compare the effectiveness of the two extraction methods on the antimicrobial quality of the extracts, both the $\log$ reduction $(\Delta)$ and the antimicrobial efficiency index were shown in Table 1 and Table 2 . As it can be seen in both tables, even if the ultrasound (UAE) extraction allowed to obtain a large quantity of extract respect to supercritic fluid extraction (SFE), that is $5.09 \mathrm{~g}$ of extract from $20 \mathrm{~g}$ of broccoli raw stems and leaves, the quality of the extract was better for the SFE extraction method. The added value of ultrasound-assisted extraction consists properly in the great recoverywhich results in a higher dried weight product probably because of the higher capability of the implant and the easier conditions for the extraction process. Even if the quantity of the SFE extract was lower respect to the UAE extraction method, $1.01 \mathrm{~g}$ from $33 \mathrm{~g}$ of raw material, the quantity of phenols and flavonoids was greater (data not shown) and for this reason the antimicrobial efficiency index was higher for the SFE extract at both percentages and for both microbial groups. Between the two index exists a direct correlation that is evident looking both tables. In fact, when the antimicrobial index increase revealing a great log reduction respect to the control sample, as a consequence, the antimicrobial efficiency index increase. The antimicrobial index range was 1.31-2.44 for one week of experimental trial against Pseudomonas at 5\% (v/v) and decreased to $1.05-1.32$ at $2 \%(\mathrm{v} / \mathrm{v})$ extract concentration, while the corresponding antimicrobial efficiency index ranges between 1.32-2.44 in the first case and 1.05-1.32 in the second case, revealing its dependent trend from the antimicrobial action of the extract that is higher in the case of 5\% added extract. For Candida krusei the antimicrobial efficiency of the extract was more evident, revealing an active action against this microbial group, the range was about 1.82-2.26 (at 5\% v/v) and 1.01-1.23 (at 2\% v/v). As a consequence the antimicrobial efficiency index at $5 \%$ of added extract, appeared to be the higher among the two techniques, ranging between 1.82-2.26. The gap between the two extraction methods was evident looking at Table 2 were the antimicrobial index was three times less for both microbial groups. This result has been determined by the less pronunciated antimicrobial activity of the ultrasound extract. The better quality of SFE extract in terms of quality protection of polyphenols was also confirmed by Oliveira, Salvador, Smania, Smania, Mareschin \& Ferreira,(2012) which underlined that SFE provides an extraction without air and light that protects the bioactivity of the extracts. The better quality of SFE extract justified the greater antimicrobial action revealed against both Pseudomonas spp. and Candida Krusei respect to UAE extract. As it can be inferred from Table 1, the antimicrobial action against the two microbial groups increased with the increase of the tested extract concentration and was about more than double respect to UAE extract (Table 2). The antimicrobial activity towards the yeast strain was slightly more pronounced and this result was of great importance as yeasts have been implicated in the spoilage of various foods (Casey \&Dobson, 2003). Even if literature did not account for SFE and UAE polyphenols extraction from broccoli by-products, the antimicrobial action of broccoli extracts against Pseudomonas spp. was confirmed by Jaiswal et al. (2011) and Jaiswal (2012). A possible explanation of the antimicrobial action of extracted phenolic compounds is related to their ability to penetrate the bacterial cell membrane and to interfere with the genetic material (Burt, 2004). 
Table 1. Log reduction $(\Delta)$ and antimicrobial efficiency index (AE) of broccoli by-products supercritic fluid extract (SFE) towards Pseudomonas spp. and Candida krusei at 5\% and 2\% (v/v)

\begin{tabular}{|c|c|c|c|}
\hline \multirow{3}{*}{$\begin{array}{l}\text { Extraction Technique } \\
\text { Supercritic Fluid Extract (SFE) 5\% } \\
\text { Microbial Groups }\end{array}$} & \multirow{3}{*}{$\begin{array}{l}\text { Dry extract weight }\left(\mathrm{EXT}_{\mathrm{DW}}\right) \\
1.01 \mathrm{~g} \\
\text { Time (days) } \\
\end{array}$} & \multicolumn{2}{|l|}{ Broccoli by-products total mass } \\
\hline & & \multicolumn{2}{|l|}{$33 \mathrm{~g}$} \\
\hline & & $\Delta\left(\mathrm{CFU}_{\mathrm{w}} \mathrm{g}^{-1}-\log \mathrm{CFU}_{\mathrm{EXT}} \mathrm{g}^{-1}\right)$ & $\mathrm{AE}\left(\Delta / \mathrm{EXT}_{\mathrm{DW}}\right)$ \\
\hline \multirow[t]{6}{*}{ Pseudomonas spp } & 1 & 1.34 & 1.32 \\
\hline & 2 & 2.16 & 2.14 \\
\hline & 3 & 1.75 & 1.73 \\
\hline & 5 & 1.85 & 1.83 \\
\hline & 6 & 2.71 & 2.68 \\
\hline & 7 & 2.46 & 2.44 \\
\hline \multicolumn{4}{|l|}{ Candida krusei } \\
\hline & 1 & 1.84 & 1.82 \\
\hline & 2 & 2.46 & 2.43 \\
\hline & 3 & 2.94 & 2.91 \\
\hline & 5 & 2.79 & 2.76 \\
\hline & 6 & 2.21 & 2.18 \\
\hline & 7 & 2.28 & 2.26 \\
\hline \multicolumn{4}{|l|}{ Supercritic Fluid Extract (SFE) $2 \%$} \\
\hline Microbial Groups & Time (days) & $\Delta\left(\mathrm{CFU}_{\mathrm{w}} \mathrm{g}^{-1}-\log \mathrm{CFU}_{\mathrm{EXT}} \mathrm{g}^{-1}\right)$ & $\mathrm{AE}\left(\Delta / \mathrm{EXT}_{\mathrm{DW}}\right)$ \\
\hline \multirow[t]{6}{*}{ Pseudomonas spp } & 1 & 1.07 & 1.05 \\
\hline & 2 & 1.57 & 1.56 \\
\hline & 3 & 0.61 & 0.61 \\
\hline & 5 & 0.63 & 0.62 \\
\hline & 6 & 1.44 & 1.42 \\
\hline & 7 & 1.34 & 1.32 \\
\hline \multicolumn{4}{|l|}{ Candida krusei } \\
\hline & 1 & 1.02 & 1.01 \\
\hline & 2 & 1.83 & 1.81 \\
\hline & 3 & 2.15 & 2.13 \\
\hline & 5 & 1.60 & 1.58 \\
\hline & 6 & 1.42 & 1.40 \\
\hline & 7 & 1.24 & 1.23 \\
\hline
\end{tabular}

Log CFUw represents the cell load of control sample that is water and $\log \mathrm{CFU}_{\mathrm{EXT}}$ the cell load of broccoli extracts. EXT $\mathrm{DWW}_{\mathrm{DW}}$ is the dry weight of the extract obtained by means of SFE extraction technique. 
Table 2. Log reduction $(\Delta)$ and antimicrobial efficiency index (AE) of broccoli by-products extract obtained by ultrasound-assisted extraction (UAE), against Pseudomonas spp. and Candida krusei at 5\% and 2\% (v/v)

\begin{tabular}{|c|c|c|c|}
\hline Extraction Technique & Dry extract weight $\left(\mathrm{EXT}_{\mathrm{DW}}\right)$ & \multicolumn{2}{|c|}{ Broccoli by-products total mass } \\
\hline Ultrasound Assisted Extract (UAE) 5\% & $5.09 \mathrm{~g}$ & \multicolumn{2}{|l|}{$20 \mathrm{~g}$} \\
\hline Microbial Groups & Time (days) & $\Delta\left(\mathrm{CFU}_{\mathrm{w}} \mathrm{g}^{-1}-\log \mathrm{CFU}_{\mathrm{EXT}} \mathrm{g}^{-1}\right)$ & $\Delta / \mathrm{EXT}_{\mathrm{DW}}$ \\
\hline \multirow{6}{*}{ Pseudomonas spp } & 1 & 0.39 & 0.08 \\
\hline & 3 & 0.46 & 0.09 \\
\hline & 4 & 0.96 & 0.19 \\
\hline & 5 & 0.93 & 0.18 \\
\hline & 6 & 0.92 & 0.18 \\
\hline & 7 & 1.05 & 0.21 \\
\hline \multirow{6}{*}{ Candida krusei } & 1 & 0.52 & 0.10 \\
\hline & 3 & 0.53 & 0.10 \\
\hline & 4 & 0.65 & 0.13 \\
\hline & 5 & 0.81 & 0.16 \\
\hline & 6 & 0.69 & 0.14 \\
\hline & 7 & 0.64 & 0.13 \\
\hline \multicolumn{4}{|l|}{ Ultrasound Assisted Extract (UAE) 2\% } \\
\hline Microbial Groups & Time (days) & $\Delta\left(\mathrm{CFU}_{\mathrm{w}} \mathrm{g}^{-1}-\log \mathrm{CFU}_{\mathrm{EXT}} \mathrm{g}^{-1}\right)$ & $\Delta / \mathrm{EXT}_{\mathrm{DW}}$ \\
\hline \multirow{6}{*}{ Pseudomonas spp } & 1 & 0.33 & 0.07 \\
\hline & 3 & 0.40 & 0.08 \\
\hline & 4 & 0.20 & 0.04 \\
\hline & 5 & 0.25 & 0.05 \\
\hline & 6 & 0.36 & 0.07 \\
\hline & 7 & 0.76 & 0.15 \\
\hline \multirow{6}{*}{ Candida krusei } & 1 & 0.20 & 0.04 \\
\hline & 3 & 0.02 & 0.003 \\
\hline & 4 & 0.33 & 0.07 \\
\hline & 5 & 0.56 & 0.11 \\
\hline & 6 & 0.34 & 0.07 \\
\hline & 7 & 0.54 & 0.11 \\
\hline
\end{tabular}

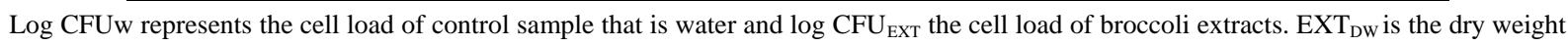
of the extract obtained by means of UAE extraction technique.

\subsection{Shelf Life of Fish Burgers with Broccoli by-products Extracts}

On the basis of the better antimicrobial activity revealed by supercritic fluid extraction (SFE) broccoli by-products extracts, the highest percentages $(5 \% \mathrm{v} / \mathrm{v})$ in vitro evaluated was added to sea-bream formulation (EXT). As control, burgers with the same quantity of ethanol (ETH) and without any addition were considered. The ethanol was chosen because SFE requires the recovery of the residue with ethanol and for this reason it was decided to consider the possible contribute of ethanol to the microbial quality of the burgers. There are few studies in the literature about the use of food by-products in real food matrix and to the best of our knowledge there are only studies about the antimicrobial effect of broccoli extracts in vitro but not in real application then, our study represents an innovation not only because compares two actual and sustainable extraction techniques but also because it suggests a concrete application to ready-to-eat fish.

Figure 1 shows the trend of total mesophilic bacteria and it is evident that the two samples with ethanol and broccoli extract revealed a slow growth. The EXT sample was the best in term of time to reach the microbial limit for the mesophilic bacteria, in fact it reached the limit at day 12.84 and so 3.91 day later respect to the sample with the same quantity of ethanol (ETH) and 10 days later respect to the control sample, confirming that the antimicrobial activity was due to the polyphenols content of the extract rather than its recovery with ethanol. 


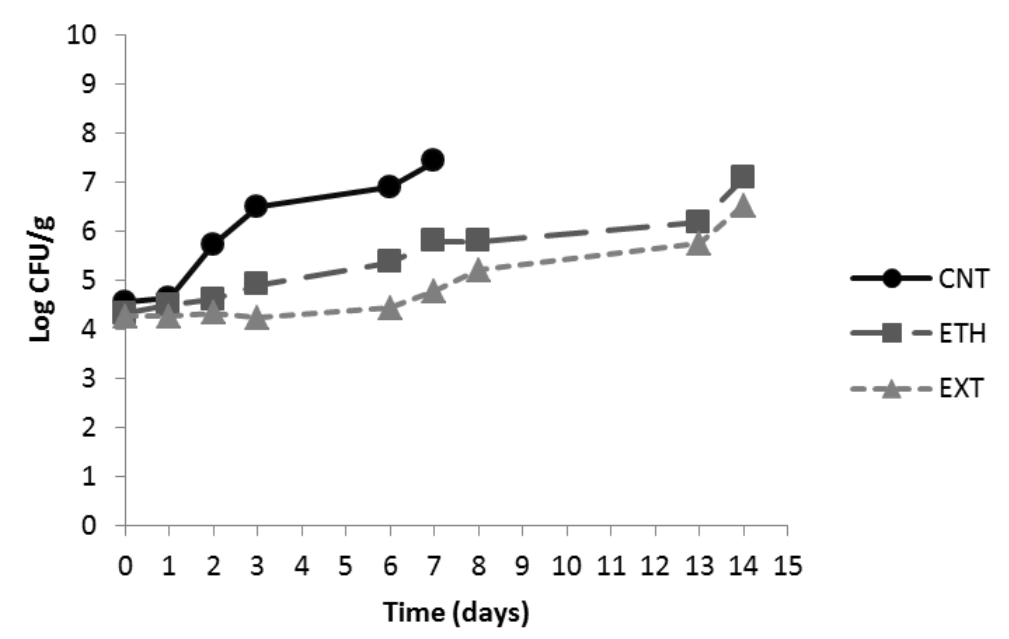

Figure 1. Evolution of mesophilic bacteria in burger samples during the storage period

For Pseudomonas spp. (Figure 2) the effect evaluated in vitro was confirmed in fish because the samples with broccoli extract never reached the microbial limit until 14 days while the control sample reached the limit after about 8 days. Also in this case ETH sample showed a little high microbial contamination with $4.28 \log \mathrm{CFU} / \mathrm{g}$ at the 13 day while the EXT sample revealed a microbial concentration of $3.74 \log \mathrm{CFU} / \mathrm{g}$ at the same day.

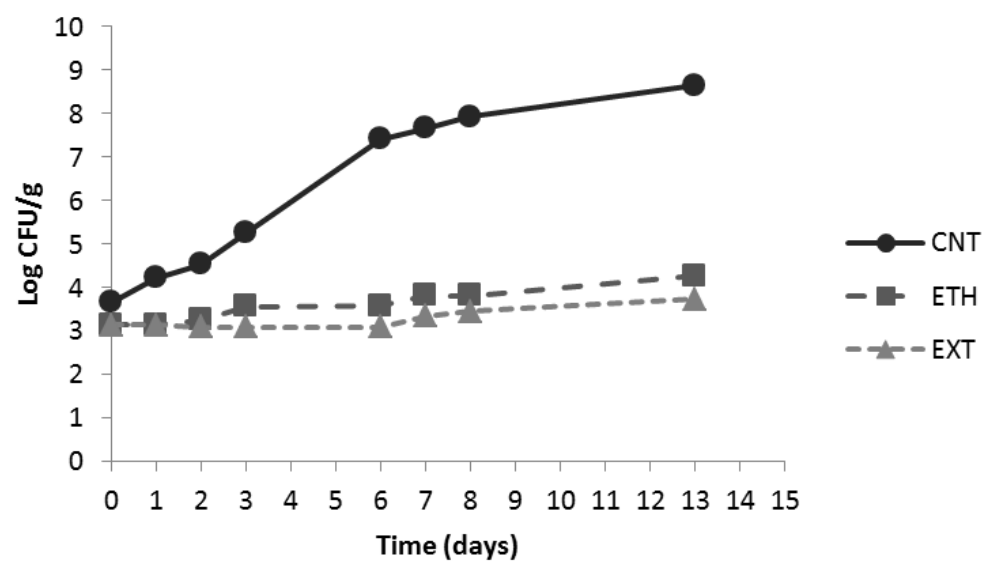

Figure 2. Pseudomonas spp. count in burger samples during the storage period

Coliforms (Figure 3) didn't represent a microbial problem for both fish burgers with broccoli extracts and ethanol while the control sample reached the limit after about one week.

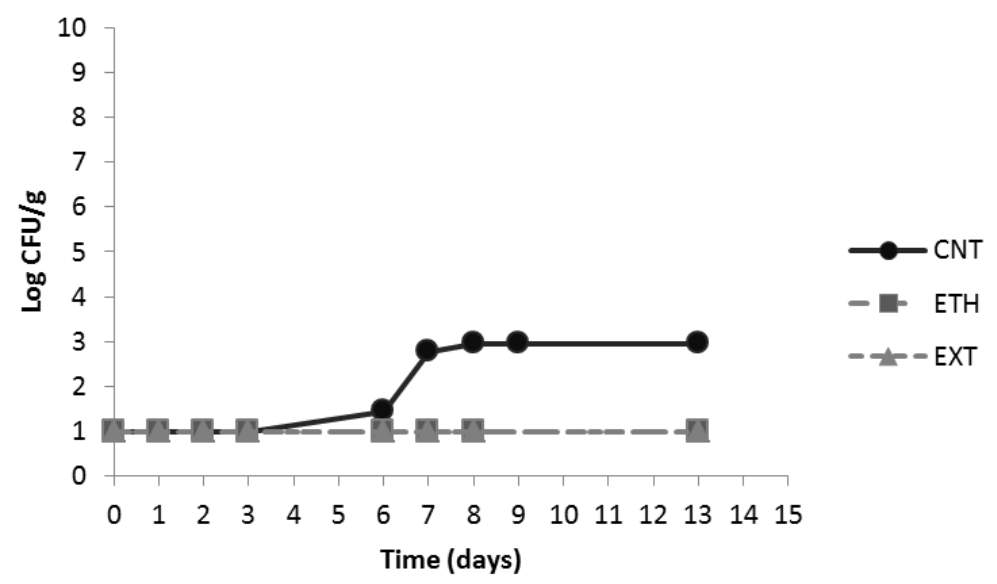

Figure 3. Evolution of coliforms in burger samples during the storage period 
For the entire experimental period there was no growth of hydrogen sulphide-producing bacteria (data not shown). As regard yeasts, samples with extract revealed a microbial growth two logarithmic order lower than the control samples (data not showed).

All samples developed in this study were also judged for sensory properties (Figure 4). All samples recorded a gradual decrease as a consequence of the microbial contamination but the ETH burgers were the less appreciated because of their pungent odor and excessive whitening effect determined by the ethanol addition that also caused a decrease of burger consistence. These samples were accepted until about one week. The CNT samples reached the sensory acceptability limit in concomitance with the Pseudomonads growth, in fact the sensory limit was reached almost simultaneously after 7 days. On the contrary, the addition of broccoli extract did not affect the sensory quality because the EXT samples reached the sensory limit more than 7 days of storage, probably due to the better microbiological preservation of the fish products. Sea-bram burgers shelf life is also listed in Table 3 as the lowest value between MAL and SAL (Conte et al., 2009). It can be inferred from data that final shelf life was limited by the sensory quality of raw samples. In general the addition of broccoli extract has led to a better microbial quality without extremely sacrificing the sensory quality. Therefore, the broccoli extract addition to sea-bram burgers determined a significant shelf life prolongation compared to control samples.

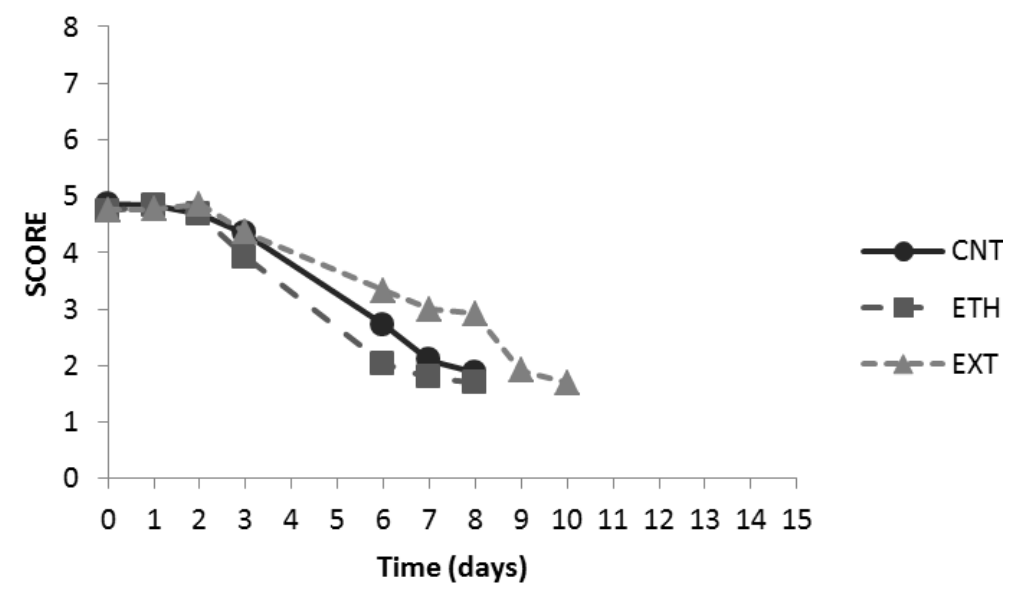

Figure 4. Uncooked burgers sensory quality during the storage period

Table 3. Microbiological quality, sensory quality and shelf life (day) of sea-bream burger samples calculated as the lowest value between microbial acceptability limit (MAL) and sensory acceptability value (day \pm SD).

\begin{tabular}{ccccccc}
\hline \multirow{2}{*}{ Samples } & \multicolumn{3}{c}{ Microbial quality (day) } & Sensory quality (day) & Shelf life (day) \\
\cline { 2 - 6 } & & MAL $^{\mathrm{APC}}$ & $\mathrm{MAL}^{\text {Pseudomonas }}$ & $\mathrm{MAL}^{\text {Coliform }}$ & SAL $^{\text {O.Q. }}$ & \\
\hline \multirow{2}{*}{$\mathrm{T}=4^{\circ} \mathrm{C}$} & $\mathrm{CNT}$ & $2.33 \pm 0.22 \mathrm{a}$ & $7.88 \pm 0.27$ & $6.97 \pm 0.23$ & $7.48 \pm 0.14 \mathrm{~b}$ & $2.33 \pm 0.22 \mathrm{a}$ \\
& $\mathrm{ETH}$ & $8.93 \pm 0.75 \mathrm{~b}$ & $>14$ & $>14$ & $7.30 \pm 0.25 \mathrm{a}$ & $7.30 \pm 0.25 \mathrm{~b}$ \\
& $\mathrm{EXT}$ & $12.84 \pm 0.71 \mathrm{c}$ & $>14$ & $>14$ & $9.15 \pm 0.50 \mathrm{c}$ & $9.15 \pm 0.50 \mathrm{c}$ \\
\hline
\end{tabular}

\section{Conclusions}

By-products represent a relevant problem for the food supply chain therefore their reuse in a sustainable way may offer the possibility to reduce the environmental impact linked to their disposal. In this study two extraction techniques were compared for their ability to preserve the bioactivity of broccoli by-products polyphenols. In vitro antimicrobial tests confirmed the ability of supercritic fluid extraction (SFE) to obtain an high quality extract in terms of antimicrobial efficiency against two tested microorganisms. The SFE extract was subsequently added to fish burgers in order to confirm its antimicrobial activity also in a real food system. In general the addition of broccoli extract has led to a better microbial quality without extremely sacrificing the sensory quality. Broccoli extract addition to sea-bream burgers determined a shelf life extension greater than one week while the corresponding control sample resulted unacceptable already after two days

\section{References}

Altieri, C., Speranza, B., Del Nobile, M. A., \& Sinigaglia, M. (2005). Suitability of bifidobacteria and thymol as biopreservatives in extending the shelf life of fresh packed plaice fillets. Journal of Applied Microbiology, 
99, 1294-1302. https://doi.org/10.1111/j.1365-2672.2005.02740.x

Angiolillo, L., Conte, A., \& Del Nobile, M. A. (2017). Microencapsulated Lactobacillus reuteri combined with modified atmosphere as a way to improve tuna burger shelf life. International Journal of Food Science and Technology, 52, 1576-1584. https://doi.org/10.1111/ijfs.13430

Arnáiz, E., Bernal, J., Martín, M. T., Diego, J. C., Bernal, J. L., \& Toribio, L. (2016). Optimization of the supercritical fluid extraction of antioxidants from broccoli leaves. Food Analytical Methods, 9, 2174-2181. https://doi.org/10.1007/s12161-016-0399-4

Baydar, N. G., Ozkan, G., \& Sagdic, O. (2004). Total phenolic content and antibacterial activities of grape extracts. Food Control, 15, 335-339. https://doi.org/10.1016/S0956-7135(03)00083-5

Botterweck, A. A. M., Verhagen, H., Goldbohm, R. A., Kleinjans, J., \& Van den Brandt, P. A. (2000). Intake of butylated hydroxyanisole and butylated hydroxytoluene and stomach cancer risk: results from analysis in the Netherlands Cohort Study. Food and Chemical Toxicology, 38, 599-605. https://doi.org/10.1016/S0278-6915(00)00042-9

Brunner, G. (2005). Supercritical fluids: technology and application to food processing. Journal of Food Engineering, 67, 21-33. https://doi.org/10.1016/j.jfoodeng.2004.05.060

Burt, S. (2004). Essential oils: their antibacterial properties and potential applications in foods-a review. International Journal of Food Microbiology, 94, 223-253. https://doi.org/10.1016/j.ijfoodmicro.2004.03.022

Casei, G. D., \& Dobson, A. D. W. (2003). Molecular detection of Candida krusei contamination in fruit juice using the citrate synthase gene cs1 and a potential role for this gene in the adaptive response to acetic acid. Journal of Applied Microbiology, 95, 13-22. https://doi.org/10.1046/j.1365-2672.2003.01940.x

Conte, A., Gammariello, D., Di Giulio, S., Attanasio, M., \& Del Nobile, M. A. (2009). Active coating and modified-atmosphere packaging to extend the shelf life of Fior di Latte cheese. Journal of Dairy Science, 92, 887-894. https://doi.org/10.3168/jds.2008-1500

Conte, A., Mastromatteo, M., Cozzolino, F., Lecce, L., \& Del Nobile, M. A. (2011). Recipe Optimization to Produce Functional Food Based on Meat and Fish. Journal of Human Nutrition and Food Science.

Correa, C. B., Martin, J. G. P., Alencar, S. M., \& Porto, E. (2014). Antilisterial activity of broccoli stems (Brassica oleracea) by flow cytometry. International Research Food Journal, 21, 395-399. https://doi.org/10.1111/jam.13629

Dalgaard, P., Gram, L., \& Huss, H. H. (1993). Spoilage and shelf life of cod fillets packed in vacuum or modified atmospheres. International Journal of Food Microbiology, 19, 283-294. https://doi.org/10.1016/0168-1605(93)90020-H

Del Nobile, M. A., Corbo, M. R., Speranza, B., Sinigaglia, M., Conte, A., \& Caroprese, M. (2009). Combined effect of MAP and active compounds on fresh blue fish burger. International Journal of Food Microbiology, 135, 281-287. https://doi.org/10.1016/j.ijfoodmicro.2009.07.024

Gill, A. O, Delaquis, P., Russo, P., \& Holley, R. A. (2002). Evaluation of antilisterial action of cilantro oil on vacuum packed ham. International Journal of Food Microbiology, 73, 83-92. http://dx.doi.org/10.1080/19476337.2013.

Gonzalez'-Centeno, M. R., Knoerzer, K., Sabarez, H., Simal, S., Rossello,' C., \& Femenia, A. (2014). Effect of acoustic frequency and power density on the aqueous ultrasonic-assisted extraction of grape pomace (Vitis vinifera L.) - a response surface approach. Ultrasonics Sonochemistry, 21, 2176-2184. https://doi.org/10.1016/j.ultsonch.2014.01.021

International Commission on Microbiological Specifications for Foods (ICMSF). (1986). Sampling plans for fish and shellfish, Microorganisms in Foods 2, Sampling for Microbiological Analysis: Principles and Scientific Applications, 2nd edition. University of Toronto Press, Toronto, Canada, 181-196.

Jaiswal, A. K., Gaurav, R., Abu-Ghaunam, N., \& Gupta, S. (2011). Phenolic composition, antioxidant capacity and antibacterial activity of selected Irish Brassica vegetables. Natural Products Comunications, 6, 1-6.

Jaiswal, A., Nissreen, A. G., \& Gupta, S. (2012). A comparative study on the polyphenolic content, antibacterial activity and antioxidant capacity of different solvent extracts of Brassica oleracea vegetables. International Journal of Food Science and Technology, 47, 223-231. https://doi.org/10.1111/j.1365-2621.2011.02829.x 
Keck, A. S., \& Finley, J. W. (2004). Cruciferous vegetables: cancer protective mechanisms of glucoinolate hydrolysis products and selenium. Integrative Cancer Therapy, 3, 5-12. https://doi.org/10.1177/1534735403261831

Koutsoumanis, K., \& Nychas, G. J. E. (2000). Application of a systematic experimental proce-dure to develop a microbial model for rapid fish shelf life predictions. International Journal of Food Microbiology, 60, 171-184. https://doi.org/10.1016/S0168-1605(00)00309-3

Martin, J. G. P., Porto, E., Correa, C. B., Alencar, S. M., Gloria, E. M., Cabral, I. S. R., \& Arquino, L. M. (2012). Antimicrobial potential and chemical composition of agro-industrial wastes. Journal of Natural Products, 5, 27-36.

Nordic Committee on Food Analysis (NCFA) (2006). Aerobic count and specific spoilage organisms in fish and fish products. NMKL method No 184, Espoo, Finland.

Oliveira, D. A., Salvador, A. A., Smania, A., Smania, E. F. A., Mareschin, M., \& Ferreira, S. R. S. (2012). Antimicrobial activity and composition profile of grape pomace extracts obtained by supercritical fluids. Journal of Biotechnology, 164, 423-432. https://doi.org/10.1016/j.jbiotec.2012.09.014

Pormortazavi, S. M., \& Hajimirsadegui, S. H. (2007). Supercritical fluid extraction in plant essential and volatile oil analysis. Journal of Chromatography, 163, 2-24. https://doi.org/10.1016/j.chroma.2007.06.021

Sibi, G., Abhilasha, S., Dhananjava, K., Rovikumar, K. R., \& Mallesha, H. (2013). In vitro antimicrobial activities of Broccoli against food borne bacteria. Journal of Applied Pharmaceutical Science, 3, 100-103.

Silva, T. I., Bernardo, E. C., Nobre, B., Mendes, R. I., \& Reis, A. (2008). Extraction of Victoria and Red Globe grape seed oil using supercritical fluid carbon dioxide with and without ethanol. Journal of Food Lipids, 15, 356-369. https://doi.org/10.1111/j.1745-4522.2008.00124.x

Widsten, P. (2014). Tannins and extracts of fruit byproducts: antibacterial activity against foodborne bacteria and antioxidant capacity. Journal of Agriculture and Food Chemistry, 62, 11146-11156. https://doi.org/10.1021/j5503819t

Wijingaard, H. H., Roble, C., \& Brunton, N. (2009). A Survey of Irish fruit and vegetable waste and by-products as a source of polyphenolic antioxidants. Food Chemistry, 116, 202-207.

https://doi.org/10.1016/j.foodchem.2009.02.033

\section{Copyrights}

Copyright for this article is retained by the author(s), with first publication rights granted to the journal.

This is an open-access article distributed under the terms and conditions of the Creative Commons Attribution license (http://creativecommons.org/licenses/by/4.0/). 